\title{
Д.С. Туляков
}

\section{АНГЛИЙСКИЙ МОДЕРНИЗМ ЗА ПРЕДЕЛАМИ КАНОНА: ПОВЕСТВОВАТЕЛЬНАЯ ТРАДИЦИЯ И НОВАТОРСТВО В «РАССКАЗАХ СИМПСОНА» М. СИНКЛЕР}

\begin{abstract}
Средствами стилистического и нарратологического анализа показано, что иикл М. Синклер «Рассказы Симпсона» представляет собой модернистское исследование сознания рассказчика. Обращаясь к традиционной форме повествования от первого лица, Синклер демонстрирует, что рассказывание историй о других является средством, которое помогает рассказчику избежать осознания правды о себе. Альтернативный модернизм М. Синклер ставит под вопрос попытки ее современников изобразить содержание сознания человека напрямую.

Ключевые слова: модернистский рассказ; Мэй Синклер; английский модернизм; повествование от первого лица; характеризация.
\end{abstract}

\section{Рассказы М. Синклер в контексте модернизма}

Богатое и многогранное наследие английской писательницы Мэй Синклер (May Sinclair, 1863-1946) представляет для исследователей и читателей нишевый, но постоянно растущий интерес. Как и другие художники начала XX в., Синклер пристально исследует место человека в радикально изменившемся современном мире и часто в новаторских формах проверяет, насколько искусство способно быть выражением человеческой сущности. Однако в отличие от своих более известных современников Синклер оказалась почти забытой после завершения литературной карьеры в начале 1930-х гг. Причинами забвения Синклер стали несовместимость ее творчества с «высоким» (и преимущественно мужским) английским модернизмом, неровное качество ее романов и широта ее интересов (это не только художественная проза, но и поэзия, философия, публицистика, литературная критика и психоанализ), из-за которой определить место писательницы в истории модернизма достаточно сложно [1. Р. 23-24]. Еще больше усложняет положение Синклер в рамках модернизма ее огромный и мгновенный читательский успех: например, в одних только Соединенных Штатах было продано около двух миллионов экземпляров ее романа «Божественный огонь» (1904) [2. Р. 1]. Популярность книг Синклер у самой широкой публики не вписывается в представления о модернистской литературе как намеренно затрудненной для восприятия и элитарной.

В то же время Синклер была значимой фигурой в модернистских кругах и писала романы, которые сегодня причисляют к литературному модернизму. Она поддерживала в печати таких писателей, как Т.С. Элиот, Э. Паунд, Х.Д. (Хильда Дулитл) и Д. Ричардсон, и часто публиковалась в тех же журналах, что и другие модернисты [3. Р. 182-209]. Например, в 
1919 г. ее роман «Мэри Оливер» выходил в одних с «Улиссом» Дж. Джойса выпусках журнала «Литтл Ревью», а в 1922 г. Т.С. Элиот включил рассказ Синклер «Жертва» в первый номер журнала «Крайтерион» вместе со своей поэмой «Бесплодная земля». Кроме того, Синклер была первым критиком, применившим выражение «поток сознания» (stream of consciousness) к модернистской прозе (в рецензии 1918 г. на романы Ричардсон) и сама экспериментировала с фрагментированной передачей сознания в таких романах, как «Мэри Оливер» (1919) и «Жизнь и смерть Хэрриет Фрин» (1922). Отмечается, что проза Синклер стоит в одном ряду с творчеством Ричардсон, Вулф и Мэнсфилд [4. Р. 96]. При этом для исследователей модернизма наибольший интерес представляет именно повествовательное новаторство в поздних романах Синклер, которое «сближает ее с другими модернистами, экспериментирующими с повествовательной точкой зрения, компрессией времени, нарушениями последовательности, недосказанностью, ироническими развязками и моментами эпифании» [5. Р. 57].

В отличие от романов рассказы Синклер редко рассматриваются в контексте модернизма. Отчасти это объясняется тем, что большинство из них выходили в популярной периодике, а не в модернистских «маленьких журналах» (как печатавшиеся в «Ритме» рассказы Мэнсфилд) или сразу же в виде книги (как «Дублинцы» Джойса или «Понедельник или вторник» Вулф). Кроме того, в основе рассказов Синклер лежит занимательная законченная история, что нехарактерно для более медитативных и как будто бессюжетных рассказов, например, Мэнсфилд или Джойса. Наконец, рассказы Синклер не претендуют на радикальное языковое новаторство и переосмысление жанра рассказа, как, например, отрывочная и ассоциативная короткая проза Вулф.

В то же время отмечается, что рассказы Синклер и других модернистов (а именно Вулф, Мэнсфилд, Ричардсон) объединяет сходное понимание человеческой субъективности как проблематичной, неустойчивой и противоречивой сущности. Для рассказов Синклер, как и других модернистов, характерна «лиминальность», т.е. сосредоточенность на «неразрешимых конфликтах идентичности, кратких проблесках пограничных состояний», на «ускользающей ощутимости бытия, которая помещает всех, кто ее ненадолго испытывает, за пределы структур социальных условностей и норм измеримого пространства и времени» [6. Р. 1]. Другая особенность рассказов Синклер - обращение к образам материальной и деформированной телесности, которое подчеркивает «эстетическое напряжение между духовной формой субъективного сознания, часто ассоциирующегося с модернистской эпифанией... и физической, плотской сексуальностью» [7. Р. 213]. Рассказы Синклер в модернистском ключе оспаривают идею о цельной, стабильной и рационально мотивированной личности, вместо этого представляя ее бытие как «непрерывное противостояние между сублимацией и отвращением» [7. Р. 228].

Согласно данной трактовке модернизм рассказов Синклер проявляется в их конфликте, тематике и особенностях образного строя. Как и в поздних 
романах Синклер, в рассказах этим особенностям соответствуют «узнаваемо модернистский эллиптичный синтаксис и фрагментированное повествование» [7. Р. 229]. Подобные интерпретации, с одной стороны, необоснованно приписывают рассказам Синклер экстравагантный модернистский стиль на уровне фразы и предложения, с другой - игнорируют специфику речевой организации рассказа в целом. Между тем обращение к особенностям повествования позволяет не только подкрепить выводы о характерно модернистской концепции субъективности в рассказах Синклер, но и точнее определить ее специфику.

Как показывает цикл рассказов о художественной и светской жизни Лондона «Рассказы Симпсона» (Tales Told by Simpson, 1930), Синклер придает особую значимость рассказчику и акту рассказывания. При этом принадлежность цикла к жанру традиционного рассказа (tales) и форма повествования от первого лица идут вразрез с узнаваемо модернистскими тенденциями к жанровому эксперименту и более «непосредственной» передаче сознания и ощущений героев. В «Рассказах Симпсона» обнаруживается, что в том, как человек рассказывает истории о других, его личность явлена не меньше, чем в потоке сознания. Более того, в рассказе проявляются такие черты говорящего, которые в силу его предвзятости, зависимости от идеологических установок и подсознательных мотивов могут быть скрыты от него самого. Фокусируясь на процессе рассказывания, а не мыслительной деятельности, Синклер ставит под вопрос возможность непосредственного доступа к субъективности посредством техники потока сознания или несобственно-прямой речи и в то же время предлагает альтернативный подход к ее локализации.

\section{Рассказ и рассказчик в «Рассказах Симпсона»}

Жанровый маркер tale (рассказ, сказание) в названии «Рассказы Симпсона» соотносит книгу Синклер с определенной традицией в истории английской короткой прозы. С XIII в. это слово обладало достаточно общим значением и использовалось для обозначения практически любого повествования - как вымышленного, так и основанного на исторических фактах [8]. К началу XIX в. оно закрепляется за «повествованиями с реалистическим основанием, в которых невзыскательный сюжет представлен с небольшим размахом. Они отличаются от романа отсутствием больших художественных притязаний» [9. Р. 369]. Ключевыми коннотациями слова tale становятся простота, повествовательность и преемственность традиций устного рассказывания историй в эпоху, предшествовавшую широкому распространению печати. Исследователи пишут о начале и конце XIX в. как о времени «подъема» [10] и «процветания» [11. Р. 6] традиционного рассказа (tale) на фоне «скетчей, анекдотов, литературных эссе и других не поддающихся классификации форм» короткой прозы [12. Р. 75]. Предметом повествования в традиционном рассказе становятся такие истории, которые достойны того, чтобы быть рассказанными и пересказанными - 
например, в силу своего поучительного содержания или значимости (или необычности) событий, о которых повествуется [11. С. 17-18]. К началу $\mathrm{XX}$ в. обозначение tale не утрачивает своих ассоциаций с традиционным устным повествованием и продолжает использоваться для характеристики рассказов наряду с жанровым обозначением short story, лишенным таких коннотаций. Слово tales фигурирует в названиях многих популярных книг рассказов английских авторов начала XX в., в том числе Р. Киплинга, Дж. Конрада, А. Беннета, Г. Уэллса и А. Конан-Дойля.

Как и жанровая идентификация, повествование от первого лица в «Рассказах Симпсона» подчеркивает их ориентацию на традицию, а не на новаторские тенденции рассказа начала XX в. Повествование от первого лица крайне характерно для викторианского рассказа. Например, Диккенс отмечал, что у рассказа лишь две ключевые черты: относительная краткость и изустный характер [13. Р. 4]. Сквозной рассказчик, объединяющий несколько историй, является отличительной чертой английской региональной короткой прозы XIX в. В книгах рассказов М.Р. Митфорд, Дж. Элиот, Э. Гаскелл, М. Олифант и других писателей сквозной рассказчик выполняет роль проводника и путеводителя по хорошо знакомым ему местам. Повествование от первого лица в данном случае выступает инструментом обращения к «устной традиции сельского рассказа прошлого, которая удовлетворяла потребность все более урбанизированного городского населения в деревенском, региональном и родовом» [14. Р. 71]. Таким образом, уже в XIX в. повествование от первого лица в книге рассказов приобретает функцию маркера традиционализма.

Многие критики соглашаются, что модернистский рассказ был реакцией «на моральную тенденциозность, которой была отмечена литература конца XIX в. и которая была во многом следствием использования в повествовании точки зрения всеведущего рассказчика» [15. С. 175]. Если в рассказе XIX в. рассказчик, часто напрямую соотносимый с автором, «сопровождает читателя, гарантируя аутентичность истории и задавая определенные нравственные координаты», то в модернистском рассказе авторитет такого рассказчика оспаривается и «акцент неизбежно смещается с фабулы и нравственного посыла на суггестивность, символизм и атмосферность» [16. Р. 149-50]. Место рассказчика в классических рассказах Джойса, Вулф или Мэнсфилд часто занимает несобственно-прямая речь - голос повествователя, свободно сливающийся с голосами и сознанием персонажей [11. С. 1]. Именно благодаря исчезновению авторитетного рассказчика модернистский рассказ приобретает свою узнаваемую эллиптичность и неоднозначность [17. Р. 44] и становится локусом инновации и эксперимента.

В «Рассказах Симпсона» повествовательная инстанция рассказчика сохраняется, но подвергается значительному переосмыслению. Синклер моделирует ситуацию устного обращения рассказчика к слушателю с историей о событиях, в которых он принимал участие или о которых он хорошо осведомлен, однако в то же время «Рассказы Симпсона» далеки от традиций викторианского рассказа. Во-первых, в отличие от рассказчиков реги- 
ональной короткой прозы XIX в. Роли Симпсон принадлежит городской среде и его рассказы ориентированы не на прошлое, а на современность. Симпсон - лондонский художник, чьи истории посвящены представителям художественной богемы и светской элиты. Во-вторых, рассказчик Синклер лишен повествовательного и морального авторитета рассказчиков викторианского рассказа, в котором повествование от первого лица призвано подчеркнуть достоверность рассказываемой истории. Рассказы Синклер представляют собой не гарантированно достоверное описание определенных событий, а набор интерпретаций, окрашенных субъективным восприятием Симпсона. Рассказчик - искушенный и тонкий наблюдатель, который, однако, воспринимает то, о чем говорит, с пристрастной и ограниченной точки зрения, - приобретает не меньшую значимость, чем истории, которые он рассказывает. Таким образом, Синклер придает устойчивому элементу поэтики традиционного рассказа новое содержание. В «Рассказах Симпсона» повествование от первого лица утрачивает прозрачность и прямолинейность; сам же рассказ предстает как текст, на разных уровнях обусловленный личностью говорящего, в том числе его социальной принадлежностью и мотивами, отсылающими к подсознательному.

\section{Рассказчик как предмет изображения}

Специфику образа рассказчика в книге Синклер целесообразно рассмотреть с позиций современной концепции (characterisation). В самом общем смысле характеризация - это процесс, в ходе которого вымышленный персонаж наделяется в восприятии читателя «определенным свойством или свойствами, характеризующими его тело, сознание, поведение или взаимоотношения с (социальным) окружением» [18. Р. 32]. В когнитивно-ориентированных теориях подчеркивается, что в этот процесс вовлечены два типа обработки входных данных: «сверху вниз» (top-down processing) и «снизу вверх» (bottom-up processing) [19, 20]. При обработке информации «сверху вниз» читатель отталкивается от собственных фоновых знаний о людях и мире. Эти упрощенные представления хранятся в долговременной памяти в виде стереотипных социальных схем (social schemata), для активации которых достаточно простого упоминания категориальной принадлежности персонажа (например, к той или иной профессии или возрастной группе). Помимо этого на создание образа персонажа «сверху вниз» влияют знания читателя о традиционных типах действующих лиц и их функциях в том или ином жанре. Обработка информации «снизу вверх» в большей степени опирается на текст конкретного художественного произведения и учитывает индивидуальные особенности персонажа, в том числе те, которые не соотносятся (или не до конца соотносятся) с изначально выбранной для него социальной схемой. Как правило, в процессе чтения оба данных когнитивных механизма характеризации выступают во взаимодействии: образ персонажа, основывающийся на стандартных социальных схемах, уточняется и модифицируется по мере того, как читатель узнает о нем все больше нового. 
В литературном произведении характеризация почти всецело зависит от текста (хотя обложка книги, иллюстрации или даже известная экранизация могут на нее влиять). Соответственно, большинство моделей характеризации основываются на выявлении текстовых сигналов, несущих в себе значимую для формирования образа персонажа информацию. В зависимости от принципа классификации сигналы характеризации подразделяются на эксплицитные (прямое называние черт персонажа) и имплицитные (действия персонажа, его внешность, окружение, речь); характеризующие говорящего персонажа (автохарактеристика) или персонажа, о котором говорят; относящиеся к уровню коммуникации «персонаж - персонаж», «нарратор - наррататор» или «автор - читатель» [21]. При этом текстовые указания, принадлежащие любой из этих категорий, могут активировать моделирование персонажа как «сверху вниз», так и «снизу вверх». В совокупности эти категории задают матрицу, которая позволяет системно подойти к анализу образа конкретного персонажа.

Так как Симпсон - рассказчик, то главным источником информации о нем является его речь. Даже в тех случаях, когда Симпсон приводит слова других персонажей, он решает, какие реплики включить в свой рассказ, а какие - нет; поэтому даже чужая речь в передаче рассказчика становится инструментом его автохарактеристики. Кроме того, так как рассказчик почти никогда не называет свои личные качества напрямую, предпочитая описывать свои действия и поступки или же рассказывать о других людях, его автохарактеристика является по преимуществу имплицитной, производной от его повествования. Наконец, то, что повествование в «Рассказах Симпсона» моделирует устный рассказ, означает, что значительная часть сигналов характеризации Симпсона располагается на уровне «нарратор - наррататор» (в данном случае «рассказчик - слушатель»). Безусловно, речевое поведение Симпсона в общении с другими персонажами (уровень «персонаж - персонаж») также имплицитно характеризует его. Однако, во-первых, по сравнению с повествованием подобные диалоги составляют лишь небольшую часть рассказов, а во-вторых, описание и демонстрация этого речевого поведения опосредованы и «отфильтрованы» Симпсоном-рассказчиком. В силу сказанного представленный ниже анализ образа Симпсона сосредоточен на имплицитной автохарактеристике рассказчика, реализующейся в процессе повествования.

С точки зрения нарратологии в имплицитной автохарактеристике рассказчика «участвуют все приемы построения повествования» [22. С. 70]. В. Шмид выделяет шесть категорий, к которым могут относиться эти приемы: отбор элементов повествования (персонажей, ситуаций, происшествий); конкретизация и детализация отобранных элементов; их композиция (порядковое расположение); их языковая репрезентация; их оценка; а также комментарии и обобщения рассказчика [22. С. 70]. Эти повествовательные приемы являются не менее значимыми сигналами имплицитной автохарактеристики рассказчика, чем его поступки, окружение, черты внешности и иные подробности его жизни, поэтому они также учитываются в представленном анализе. 
Последнее предварительное замечание касается характеризации на уровне коммуникации «автор - читатель». Данная характеризация иерархически включает в себя оба нижестоящих уровня, но вдобавок к этому отсылает к стратегическим авторским решениям (разделение произведения на части, название произведения и его частей, тип повествования и т.п.). Для характеризации Симпсона на уровне коммуникации «автор - читатель» значимо само авторское решение дать речь именно этому персонажу, поскольку «когда в литературном повествовании персонажу - как правило протагонисту или рассказчику - уделяется пристальное внимание, читатель может почувствовать, он “узнал” этого персонажа так, как мог бы узнать настоящего человека» [23. Р. 8]. В случае с рассказчиком столь богато реализованная характеризация может иметь место только тогда, когда его роль в произведении выходит за рамки кодификации определенных повествовательных конвенций (а в викторианском рассказе главная функция рассказчика зачастую заключалась именно в этом). Вынесенное в заглавие книги имя Симпсона указывает на значимость образа рассказчика и побуждает читателя отнестись к нему с особым вниманием.

\section{Сознание Симпсона через призму характеризации}

Отличие «Рассказов Симпсона» от таких классических викторианских книг рассказов с повествованием от первого лица, как «Очерки Боза» Ч. Диккенса или «Крэнфорд» Э. Гаскелл, в том, что Синклер делает сознание рассказчика полноправным и, пожалуй, главным предметом изображения. Рассказчики и у Диккенса, и у Гаскелл также обладают выраженной индивидуальностью и узнаваемым стилем, однако их функции по большому счету сводятся к тому, чтобы обеспечить читателю достоверный доступ к истории и передать ее в доступной и увлекательной форме. Их действия, оценки и манера вести повествование не диссонируют с историями, которые они рассказывают. В случае с Симпсоном, напротив, правомерность оценок и трактовок событий рассказчиком ставятся под вопрос, а читателю нужно приложить дополнительные усилия для того, чтобы разобраться в его психологии и мотивации. В «Рассказах Симпсона» моделирование сознания рассказчика превращается из фонового автоматического процесса в основную задачу, стоящую перед читателем. В конечном счете средства имплицитной характеризации позволяют Синклер создать сложный и психологически нюансированный образ рассказчика, личность которого во многом определяется тем, что остается скрытым от него самого или вытесненным из его сознания.

Так как «первая представленная информация о персонаже обладает первостепенной важностью для динамики восприятия его образа, поскольку дальнейшие умозаключения и предположения читателя будут определяться сформированной вначале моделью персонажа» [20. С. 619], в представленном анализе основное внимание уделено первому рассказу книги «Хаки». В «Хаки» описывается жизнь банковского служащего Майлза Ди- 
кинсона, над глупостью и нелепостью которого Симпсон и его компания любили насмехаться до тех пор, пока тот не отправился добровольцем на Англо-бурскую войну и не погиб там. Это событие заставило невесту Симпсона перестать видеть в Дикинсоне посмешище и в конечном счете расторгнуть помолвку с рассказчиком, поскольку он не согласился (и попрежнему не соглашался) с такой переоценкой.

Для читателя, моделирующего в сознании образ рассказчика, наиболее значимыми входными данными будет та информация, которую Симпсон имплицитно сообщает о себе в «Хаки», а также то, как он ведет повествование. Так как здесь, как и во всех остальных рассказах книги, Симпсон обращается к неназванному слушателю, который, очевидно, достаточно хорошо с ним знаком, многие важные с точки зрения характеризации сведения о Симпсоне даны имплицитно. Так, в самом начале рассказа читатель узнает, что в конце 1890-х гг. рассказчик, его невеста и другие люди его круга («все мы») «в условиях строгой экономии жили в Челси, на старой доброй Вейл или в ее районе» [24. Р. 3]. Это указание косвенно характеризует Симпсона как человека среднего достатка, принадлежащего артистической среде. (B XIX-XX вв. Челси был известен как район, в котором живут художники, а в 1870-е на Вейл стали строиться и сдаваться в аренду относительно недорогие студии [25].) Данные имплицитные сигналы задействованы в характеризации Симпсона «сверху вниз»: они с большой вероятностью должны запустить в сознании читателя социальную схему «богемный лондонский художник». Актуальность этой схемы для Симпсона подчеркивается использованием им формы первого лица во множественном числе («мы»), которое подразумевает, что он в полной мере причисляет себя к своему социальному окружению, а также положительнооценочной фразеологией («старая добрая Вейл»).

Характеризация «сверху вниз» также затрагивает жанровые ожидания, с которыми читатель подходит к произведению. Как было показано ранее, для викторианских книг рассказов с формой повествования от первого лица были характерны не городские, а региональные (или деревенские) рассказчики, чья надежность и достоверность лишь подкреплялась традиционной «изустной» формой их повествования. Поэтому, выбирая на роль рассказчика лондонского художника, Синклер подчеркивает его несоответствие сложившейся жанровой традиции и, таким образом, обращает на него внимание читателя.

Основными сигналами характеризации «снизу вверх», придающими Симпсону индивидуальность, являются его действия. При этом важно различать поведение повествуемого и повествующего «я» рассказчика: первое охватывает поступки Симпсона как участника событий, которые он теперь описывает своему слушателю; второе отсылает к поведению Симпсона как рассказчика и затрагивает весь комплекс его повествовательных и стилистических решений.

Действия Симпсона - участника повествуемых событий характеризуют его как человека, который ставит себя и людей своего окружения выше 
тех, кто этому окружению не принадлежит. При этом снобизм Симпсона сочетается с наблюдательностью и насмешливостью по отношению к людям иного социального положения, иных интересов и убеждений. Так, Симпсон (и, как он утверждает, вся его компания) дали Майлзу Дикинсону унизительное прозвище «хорек» - «за то, как он окопался в своем банке и с каким проворством он оставил его» [24. Р. 4]. При этом, несмотря на презрительное отношение к Дикинсону, Симпсон и его друзья не пытались избегать общения с ним, поскольку он был привлекательным объектом для их насмешек: «...мы просто не могли позволить себе отпустить его» [20. P. 3]. Впоследствии, когда невеста Симпсона Фрэнсис Арчдейл начинает воспринимать Дикинсона не как посмешище, а как неузнанного и непонятого героя, и утверждает, что всегда видела в нем доблестные качества, Симпсон не может даже допустить этого, из-за чего между ними происходит разрыв. Симпсон считал, что «эта одержимость плохо на нее влияла, и я хотел пустить в ход здравый смысл ее чувства юмора» [24. Р. 14]. Это поведение Симпсона характеризует его как человека, который полностью убежден в своей правоте и нормальности насмешливо-высокомерного отношения к другим. Ревность Симпсона говорит о том, что он видит в ином способе восприятия людей (основанном на стремлении к пониманию, уважении и сопереживании) угрозу этой «норме».

То, как Симпсон-рассказчик строит повествование, также играет роль в его характеризации, акцентируя в нем такие черты, как ограниченность, насмешливость склонность к отрицательным оценочным суждениям, убежденность в собственной правоте и отсутствие критического самосознания. В «Хаки» Симпсон выбирает для рассказа историю о человеке, который кажущемся ему недалеким, нелепым и смешным. Соответственно конкретизация и детализация этой истории направлены на то, чтобы представить Дикинсона в этом невыгодном свете. Так, Симпсон достаточно подробно описывает «странности» Дикинсона (его нереализованные фантастические изобретения, увлеченность войной и склонность к теоретизированию) и то, как его высмеивали сам Симпсон и другие художники. Часто Симпсон акцентирует детали, которые должны выставить Дикинсона менее сообразительным, чем окружающие (например, он ничем не может ответить на остроты, направленные в его сторону). С другой стороны, о таких подробностях, которые могли бы указывать на иные черты характера Дикинсона, Симпсон упоминает лишь вскользь или не упоминает вообще.

Композиция повествования Симпсона линейна и сама по себе вряд ли является инструментом его характеризации, однако стиль рассказчика и высказываемые им оценки и комментарии также участвуют в создании образа высокомерного и резкого в суждениях человека. Например, в самом начале рассказа, перед тем как сообщить что бы то ни было о Дикинсоне, Симпсон утверждает: «Невообразимо, каким он был ослом» [24. Р. 3]. Симпсон продолжает говорить о Дикинсоне в резко уничижительном ключе на протяжении всего рассказа. При этом важно, что как рассказчик, отделенный от повествуемых событий временной дистанцией, Симпсон не 
изменил своего изначально негативного отношения к Дикинсону. Так, Симпсон продолжает считать Дикинсона трусом, который только говорит о том, чтобы отправиться на войну добровольцем, но в действительности бездействует («Он был не из тех, кто ходит на войну» [24. Р. 6]) - несмотря на то, что тот в конечном счете уходит на войну добровольцем и погибает там, проявив смелость. Даже когда Симпсон описывает смерть Дикинсона, он продолжает насмехаться над ним: в передаче рассказчика, Дикинсон погиб, когда в опасной ситуации не сбежал, а «к своему превеликому удовольствию стал стрелять и был обстрелян» [24. Р. 10].

Выделенные нами в «Хаки» имплицитные сигналы характеризации Симпсона (отсылки к его социальному статусу и окружению; поведение его повествуемого «я»; особенности построения повествования) обнаруживаются во всех рассказах книги. В целом истории, которые Симпсон выбирает для рассказа, характеризуют его как человека, который считает, что он одновременно принадлежит светскому обществу и выделяется на его фоне особой проницательностью и интеллектом. События и действующие лица, о которых Симпсон рассказывает, а также его оценки и комментарии подразумевают, что он полностью разделяет интересы и взгляды своего круга; положительные высказывания о себе, которые он часто цитирует, показывают, что он придает значение одобрению со стороны окружающих. Социальное положение Симпсона обусловливает его ограниченность и предвзятость: Симпсон не только идентифицирует себя с обществом, к которому принадлежит, он не принимает и не понимает тех, кто мыслит и чувствует по-другому, занимает иное общественное положение, вызывает его ревность или же просто не соответствует его вкусу. Эти черты рассказчика проявлются в его оценках других персонажей и в том, как он строит повествование и интерпретирует события, о которых рассказывает. Например, по мнению Симпсона, нищий художник из рассказа «Картины» безоговорочно «мерзок», а его живопись - «ужасна, гораздо хуже, чем вы можете вообразить» [24. Р. 122, 129]; а героиня рассказа «Бамбино» Адела, по неосторожности уронившая и травмировавшая своего маленького ребенка, заслуживает только ненависть рассказчика (в то время как ее муж - жалость).

Уже в «Хаки» Симпсон охарактеризован как человек, неспособный сочувствовать и принимать точку зрения другого, но не видящий в этом своего недостатка и не отдающий себе в этом отчета. Слепота по отношению к себе, как одна из определяющих черт Симпсона, находит тематическую параллель в избирательной «психической» слепоте героев его рассказов. В отличие от Аделы, которая не замечает ничего необычного в своем остановившемся в развитии ребенке, дядя Симпсона в буквальном смысле на время лишается зрения - согласно психоаналитику, из-за «сильного подсознательного желания никогда больше не видеть свою жену» [24. Р. 28]. Что важнее - полковник Симпсон не осознает (или не признается себе), что испытывает ненависть к жене, поэтому его слепота, как и слепота Аделы, направлена и на него самого. Подсознательное нежелание видеть жену от- 
ражает нежелание или неспособность полковника увидеть в себе того, кем он стал, - несчастного человека, поглощенного ненавистью. Поэтому внезапная смерть жены не приносит полковнику облегчения (напротив, ему не хватает ее, и он сам умирает вслед на ней через несколько месяцев).

Рассказчик не проводит связи между собой и Аделой или полковником Симпсоном, однако его случай похож на их истории: то, чего Симпсон не видит в других, указывает на отталкивающие черты, которые он не хочет замечать в самом себе. Симпсон описывает в положительном ключе людей из своего светского окружения, в особенности тех, кто наиболее на него похож; другие же - женщины, люди низшего социального положения, пожилые, жители провинции и все те, кто руководствуется иными ценностями и образом мыслей, - чаще всего вызывают у него насмешку, непонимание или неприятие. Отказывая в сопереживании и сострадании другому, рассказчик не только утверждает свое интеллектуальное и социальное превосходство, но и демонстрирует психологическую неполноценность, в которой не отдает себе отчет.

\section{Заключительные замечания}

На фоне жанровых и языковых экспериментов таких английских модернистов, как Вулф, Джойс и Мэнсфилд, «Рассказы Симпсона» могут показаться мало примечательным набором увлекательных историй, которые отсылают к изустной традиции викторианского рассказа и хорошо вписываются в контекст популярного журнального рассказа начала XX в. В то же время особый интерес Синклер к фигуре рассказчика, проявляющего себя в процессе рассказа о других, сближает «Рассказы Симпсона» с модернистскими поисками нового понимания и новых способов художественного выражения субъективности.

Синклер, как и другие модернисты, видит в субъективности сложный, обманчивый и трудноуловимый феномен, обусловленный индивидуальными внешними факторами, особенностями и скрытыми психологическими мотивами. В «Рассказах Симпсона» сознание рассказчика представлено как своего рода замкнутая система, ориентированная на сохранение стабильности, невзирая на воздействия извне. Рассказы выступают в качестве инструмента поддержания этой стабильности: они позволяют рассказчику создать такую версию собственного «я», в которой ограниченность, предвзятость и неполноценность оказываются тщательно скрытыми от него самого. Подбор и характер рассказываемых историй, а также выраженные в них оценки и интерпретации (которые могут не разделять другие персонажи) преследуют именно эту цель. Обращаясь к форме рассказа от первого лица, Синклер подчеркивает, что субъективность обладает социальной и подсознательной природой, которая может оставаться для человека скрытой и непознанной.

На наш взгляд, именно воплощение модернистской концепции проблемной и противоречивой субъективности посредством традиционной 
формы повествования от первого лица составляет специфику модернизма рассказов Синклер. Данная трактовка «Рассказов Симпсона» позволяет избежать необоснованного приведения короткой прозы Синклер к общему знаменателю с другими модернистскими рассказами по признаку якобы общего для них новаторства на уровне языка и специфической образности. Специфика модернизма «Рассказов Симпсона» как раз в том, что, оставаясь простыми и доступными в образном и языковом отношении историями, они отражают то, как в процессе повествования сознание и подсознание формируют и проецируют многократно опосредованную субъективность рассказчика. Таким образом, интерес к рассказу как выражению внутреннего «я» говорящего во всей его сложности и противоречивости ставит Синклер в оппозицию к тем модернистам, которые стремились экспериментальными средствами зафиксировать субъективность в потоке сознания, не обращенном во внешнюю речь.

\section{Лuтература}

1. Raitt S. 'Dying to Live': Remembering and Forgetting May Sinclair // May Sinclair: Rethinking Bodies and Minds / ed. by R. Bowler, C. Drewery. Edinburgh : Edinburgh University Press, 2016. P. 21-38.

2. Bowler R., Drewery C. Introduction: May Sinclair's Interdisciplinarity// May Sinclair: Rethinking Bodies and Minds / ed. by R. Bowler, C. Drewery. Edinburgh : Edinburgh University Press, 2016. P. 1-17.

3. Raitt S. May Sinclair: A Modern Victorian. Oxford : Clarendon Press, 2000. 307 p.

4. Jones C. An Edwardian Turn of Mind: Psychological Realism and Modernist Metaphysics in May Sinclair's "The Divine Fire" // Modernism/modernity. 2018. Vol. 25. № 1. P. 193-114.

5. Pease A. Modernism, Feminism and the Culture of Boredom. N.Y. : Cambridge University Press, 2000.159 p.

6. Drewery C. Modernist Short Fiction by Women: The Liminal in Katherine Mansfield, Dorothy Richardson, May Sinclair and Virginia Woolf. Farnham : Ashgate, 2011. 150 p.

7. Drewery C. Transgressing Boundaries; Transcending Bodies: Sublimation and the Abject Corpus in "Uncanny Stories" and "Tales Told by Simpson" // May Sinclair: Rethinking Bodies and Minds / ed. by R. Bowler, C. Drewery. Edinburgh : Edinburgh University Press, 2016. P. 213-231.

8. “tale, n.” OED Online. URL: www.oed.com/view/Entry/197201 (дата обращения: 15.08.2019).

9. Guerro-Strachan S.R. Récit, Story, Tale, Novella // Romantic Prose Fiction / ed. by G. Gillespie, M. Engel, B. Dieterle. Amsterdam : John Benjamins Publishing, 2008. P. 364382.

10. Killick T. British Short Fiction in the Early Nineteenth Century: The Rise of the Tale. Farnham : Ashgate, 2008. 193 p. 189 p.

11. Hanson C. Short Stories and Short Fictions, 1880-1980. London : Macmillan, 1985.

12. Stewart D. Romantic Short Fiction. // The Cambridge Companion to the English Short Story / ed. by A. Einhaus. Cambridge : Cambridge University Press, 2016. P. 73-86.

13. Thomas D. Dickens and the Short Story. Philadelphia : University of Pennsylvania Press, $1982.196 \mathrm{p}$.

14. Gilmartin S. The Victorian Potboiler: Novelists Writing Short Stories // The Cambridge History of the English Short Story / ed. by D. Head. Cambridge : Cambridge University Press, 2016. P. 67-83. 
15. Рейнгольд Н.И. Английская литература модернизма: История. Проблематика. Поэтика. М : РГГУ, 2017. 780 с.

16. D'hoker E. The Development of Katherine Mansfield's First-person Narratives // Journal of Narrative Theory. 2012. Vol. 42, № 2. P. 149-165.

17. Hunter A. The Cambridge Introduction to the Short Story in English. N.Y. : Cambridge University Press, 2007. 202 p.

18. Eder J., Jannidis F., Schneider R. Characters in Fictional Worlds: An Introduction. // Characters in Fictional Worlds: Understanding Imaginary Beings in Literature, Film, and Other Media / ed. by J. Eder, F. Jannis, R. Schneider. Berlin : De Gruyter, 2010. P. 3-66.

19. Culpeper J. Language and Characterisation. People in Plays and Other Texts. Harlow : Longman, 2001. 328 p.

20. Schneider R. Toward a Cognitive Theory of Literary Character: The Dynamics of Mental-Model Construction // Style. 2001. Vol. 35, № 4. P. 607-639.

21. McIntyre D. Characterisation // The Cambridge Handbook of Stylistics / ed. by P. Stockwell, S. Whiteley. Cambridge : Cambridge University Press. P. 149-164.

22. Шмид В. Нарратология. М.: Языки славянских культур, 2008. 304 с.

23. Caracciolo M. Strange Narrators in Contemporary Fiction. Explorations in Readers' Engagement with Characters. Lincoln; London : University of Nebraska Press. 266 p.

24. Sinclair M. Tales Told by Simpson. London: Macmillan, 1930. 297 p.

25. Croot P. Settlement and building: Artists and Chelsea // A History of the County of Middlesex: Vol. 12, Chelsea / ed. by P. Croot. London: Victoria County History, 2004. P. 102-106.

\section{English Modernism beyond the Canon: Narrative Tradition and Innovation in May Sinclair's Tales Told by Simpson \\ Vestnik Tomskogo gosudarstvennogo universiteta. Filologiya - Tomsk State University Jour- nal of Philology. 2021. 70. 298-312. DOI: 10.17223/19986645/70/17}

Dmitriy S. Tulyakov, Higher School of Economics (Perm, Russian Federation). E-mail: dstuliakov@hse.ru

Keywords: modernist short story, May Sinclair, English modernism, first person narration, characterization.

The article considers short stories of May Sinclair (1863-1946) as a non-canonical variation of the English modernist short story. A historical overview presents Sinclair as a bestselling author of Victorian descent who was in touch with the artistic experimentation of the 19101920s. Critics point out that some of Sinclair's novels can be considered modernist due to their preoccupation with subjectivity, which is formally reflected in the author's use of "stream of consciousness". Sinclair's more traditionally narrated short stories, however, are rarely approached in a similar way and remain largely ignored, even though they are no less focused on the nature of consciousness and the problem of its representation. The second section of the article suggests that Sinclair's Tales Told by Simpson (1930) can be considered as a modernist short story cycle which aligns itself with the traditional generic form of the tale in order to rethink the status of the storyteller. On the one hand, first-person narration links Sinclair's book to the Victorian short story collections where the narrator carries on the tradition of oral storytelling and signifies the authenticity of the tale. On the other hand, in Sinclair's interpretation, first-person narration loses its transparency and reliability and becomes a means of complex portrayal of the narrator's biased perception of himself and the others. The third section introduces the framework of literary characterization which is used to analyze the image of the narrator in Tales Told by Simpson. Literary characterization is triggered by explicit and implicit textual cues, which are situated on different levels of the narrative structure of the text. For Simpson, the narrating character, the most important are implicit autocharacterization cues, which include, on the one hand, the narrator's reported actions, behavior, social environment, and attitudes, and, on the other hand, his narrative choices, 
style, and commentary. The fourth section applies the characterization framework to the analysis of the image of the narrator. Simpson's characterization suggests that the way he perceives himself and the events he tells about differs from the way the reader is likely to model Simpson and interpret his stories. Various cues contribute to the reader's impression of Simpson as an egotistical and narrow-minded person. The narrator's inability to understand and empathize with people of a different social standing, as well as his perceived sense of intellectual superiority, distorts his stories in order to hide the psychological deficiencies he is unaware of. The shift from the story to the way it is told and to what it reveals about the narrator distinguishes Tales Told by Simpson as a highly innovative short story cycle. At the same time, representation of the narrator's subjectivity from the outside by means of first-person oral narration sets Sinclair's stories in opposition to modernist experiments in direct treatment of consciousness.

\section{References}

1. Raitt, S. (2016) 'Dying to Live': Remembering and Forgetting May Sinclair. In: Bowler, R. \& Drewery, C. (eds) May Sinclair: Rethinking Bodies and Minds. Edinburgh: Edinburgh University Press. pp. 21-38.

2. Bowler, R. \& Drewery, C. (2016) Introduction: May Sinclair's Interdisciplinarity. In: Bowler, R. \& Drewery, C. (eds) May Sinclair: Rethinking Bodies and Minds. Edinburgh: Edinburgh University Press. pp. 1-17.

3. Raitt, S. (2000) May Sinclair: A Modern Victorian. Oxford: Clarendon Press.

4. Jones, C. (2018) An Edwardian Turn of Mind: Psychological Realism and Modernist Metaphysics in May Sinclair's “The Divine Fire”. Modernism/Modernity. 25 (1). pp. 193-114.

5. Pease, A. (2000) Modernism, Feminism and the Culture of Boredom. N.Y.: Cambridge University Press.

6. Drewery, C. (2011) Modernist Short Fiction by Women: The Liminal in Katherine Mansfield, Dorothy Richardson, May Sinclair and Virginia Woolf. Farnham: Ashgate.

7. Drewery, C. (2016) Transgressing Boundaries; Transcending Bodies: Sublimation and the Abject Corpus in "Uncanny Stories" and "Tales Told by Simpson". In: Bowler, R. \& Drewery, C. (eds) May Sinclair: Rethinking Bodies and Minds. Edinburgh: Edinburgh University Press. pp. 213-231.

8. OED Online. (2019) Tale, n. [Online] Available from: www.oed.com/view/Entry/ 197201 (Accessed: 15.08.2019).

9. Guerro-Strachan, S.R. (2008) Récit, Story, Tale, Novella. In: Gillespie, G., Engel, M. \& Dieterle, B. (eds) Romantic Prose Fiction. Amsterdam: John Benjamins Publishing. pp. 364-382.

10. Killick, T. (2008) British Short Fiction in the Early Nineteenth Century: The Rise of the Tale. Farnham: Ashgate.

11. Hanson, C. (1985) Short Stories and Short Fictions, 1880-1980. London: Macmillan.

12. Stewart, D. (2016) Romantic Short Fiction. In: Einhaus, A. (ed.) The Cambridge Companion to the English Short Story. Cambridge: Cambridge University Press. pp. 73-86.

13. Thomas, D. (1982) Dickens and the Short Story. Philadelphia: University of Pennsylvania Press.

14. Gilmartin, S. (2016) The Victorian Potboiler: Novelists Writing Short Stories. In: Head, D. (ed.) The Cambridge History of the English Short Story. Cambridge: Cambridge University Press. pp. 67-83.

15. Reyngol'd, N.I. (2017) Angliyskaya literatura modernizma: Istoriya. Problematika. Poetika [English Literature of Modernism: History. Problems. Poetics]. Moscow: RSUH.

16. D'hoker, E. (2012) The Development of Katherine Mansfield's First-person Narratives. Journal of Narrative Theory. 42 (2). pp. 149-165.

17. Hunter, A. (2007) The Cambridge Introduction to the Short Story in English. N.Y.: Cambridge University Press. 
18. Eder, J., Jannidis, F. \& Schneider, R. (2010) Characters in Fictional Worlds: An Introduction. In: Eder, J., Jannidis, F. \& Schneider, R. (eds) Characters in Fictional Worlds: Understanding Imaginary Beings in Literature, Film, and Other Media. Berlin: De Gruyter. pp. 3-66.

19. Culpeper, J. (2001) Language and Characterisation. People in Plays and Other Texts. Harlow: Longman.

20. Schneider, R. (2001) Toward a Cognitive Theory of Literary Character: The Dynamics of Mental-Model Construction. Style. 35 (4). pp. 607-639.

21. McIntyre, D. (2014) Characterisation. In: Stockwell, P. \& Whiteley, S. (ed.) The Cambridge Handbook of Stylistics. Cambridge: Cambridge University Press. pp. 149-164.

22. Shmid, V. (2008) Narratologiya [Narratology]. Moscow: Yazyki slavyanskikh kul'tur.

23. Caracciolo, M. (2016) Strange Narrators in Contemporary Fiction. Explorations in Readers' Engagement with Characters. Lincoln; London: University of Nebraska Press.

24. Sinclair, M. (1930) Tales Told by Simpson. London: Macmillan.

25. Croot, P. (2004) Settlement and building: Artists and Chelsea. In: Croot, P. (ed.) $A$ History of the County of Middlesex. Vol. 12, Chelsea. London: Victoria County History. pp. 102-106. 